\title{
Familial porokeratosis Mibelli
}

\section{Rodzinna postać porokeratozy Mibellego}

\author{
Katarzyna A. Tomaszewska', Małgorzata Dominiak², Anna M. Zalewska-Janowska', Andrzej Kaszuba² \\ 'Department of Psychodermatology, Chair of Clinical Immunology and Microbiology, Medical University of Lodz, Poland \\ 2Department of Dermatology, Pediatric and Oncologic Dermatology, Medical University of Lodz, Poland \\ 'Zakład Psychodermatologii Międzywydziałowej Katedry Immunologii Klinicznej i Mikrobiologii Uniwersytetu Medycznego w Łodzi, Polska \\ ${ }^{2}$ Klinika Dermatologii, Dermatologii Dziecięcej i Onkologicznej Uniwersytetu Medycznego w Łodzi, Polska
}

\section{CORRESPONDING AUTHOR/ ADRES DO KORESPONDENCJI:} lek. Katarzyna A. Tomaszewska Zakład Psychodermatologii Międzywydziałowa Katedra Immunologii Klinicznej i Mikrobiologii Uniwersytet Medyczny w Łodzi ul. Pomorska 251

(budynek C-5)

92-213 Łódź

tel.: +48 422725788

faks: +48 426782292

e-mail: tomaszewska.katarzyna@ o2.pl

\begin{abstract}
Introduction. Porokeratoses (PK) are a group of uncommon dermatoses, characterised by a keratinisation disorder, manifesting clinically with annular or linear, well-limited, keratotic plaques and histologically by the presence of the "cornoid lamella".

Objective. To present and discuss a case of the familiar porokeratosis Mibelli in 11-year-old girl and her 40-year-old mother.

Case report. We present the case of an 11-year-old girl and her 40-yearold mother with clearly demarcated, slightly atrophic annular lesions surrounded by slightly scaly hyperkeratotic ridge. In the girl, the lesions were located on the right lower limb, in the mother on both of the shins. The diagnosis was confirmed by histopathological examination. The patients were treated with topical $0.1 \%$ adapalene cream.
\end{abstract}

Conclusions. The presented case is interesting because of the family occurrence of the disease.

\section{STRESZCZENIE}

Wprowadzenie. Porokeratozy (PK) to rzadka grupa chorób skóry, których istotą jest zaburzony proces rogowacenia naskórka. Klinicznie schorzenia te charakteryzują się występowaniem obrączkowatych bądź linijnych zmian z hiperkeratotyczną obwódką i zanikiem w części środkowej. Histologiczną cechą wszystkich wariantów choroby jest obecność zrogowaciałych blaszek: corneoid lamellae.

Cel pracy. Przedstawienie i omówienie przypadku rodzinnego występowania porokeratozy Mibellego u 11-letniej dziewczynki i jej 40-letniej matki.

Opis przypadku. Przedstawiono przypadek 11-letniej dziewczynki i jej 40-letniej matki ze zmianami skórnymi w postaci wyraźnie odgraniczonych, lekko zanikowych, obrączkowatych ognisk z widoczną uniesioną, delikatnie łuszczącą się hiperkeratotyczną obwódką. U dziewczynki zmiany zlokalizowane były na prawej kończynie dolnej, a u matki na obu podudziach. Rozpoznanie potwierdzono badaniem histopatologicznym. Do leczenia u obu pacjentek włączono miejscowo $0,1 \%$ adapalen w kremie.

Wnioski. Przedstawiony przypadek jest interesujący ze względu na rodzinne występowanie schorzenia. 
Słowa kluczowe: choroby skóry, genetyka, porokeratoza, Mibelli.

Key words: skin diseases, genetic, porokeratosis, Mibelli.

\section{INTRODUCTION}

Porokeratoses (canal keratinization) constitute a rare group of chronic dermatoses that is characterized by the presence of typical morphological and histopathological features. Clinically, skin lesions manifest themselves as a papula that expands outwards and evolves into a slightly atrophic focus with a slightly scaly ridge [1].

Histopathological presentation is characterized by hyperkeratinisation with the presence of keratotic plaques, so-called cornoid lamellae, which extend from foci of thin or abnormal granular layer [2].

A classic form of the disease was described for the first time in 1893 by Vittorio Mibelli. At that time he coined the term porokeratosis, which appears to be incorrect given the current data, as the disorder is not connected to orifices of eccrine sweat glands [3]. The disease may be divided into several types (table 1) [4-6].

Not only is porokeratosis an aesthetic defect, but it is also a preneoplastic condition. The risk of transformation is estimated at $7.5-11.6 \%$ [2]. Lesions that may develop secondary to foci of porokeratosis include: spinocellular carcinoma, basal cell carcinoma, and Bowen's disease [7-9]. Skin lesions require to be actively observed. Treatment includes topical [2] or systemic retinoids [10], 5-fluorouracil formulations [11], formulations with imiquimod, diclofenac, or vitamin D analogues, cryotherapy, laser therapy, electrocoagulation, dermabrasion, photodynamic therapy, and even surgical excision of individual lesions [12].

\section{OBJECTIVE}

The aim of the study was to present and discuss a case of the familiar porokeratosis Mibelli in 11-yearold female patient and her 40-year-old mother.

\section{CASE REPORT}

An 11-year-old girl reported to the Clinic with her mother due to skin lesions manifesting themselves as clearly demarcated, slightly atrophic annular foci with a visible elevated and slightly scaly hyperkeratotic ridge. The lesions covered extensor surfaces of her upper right limb and appeared initially on the

\section{WPROWADZENIE}

Porokeratozy (rogowacenia kanalikowe) są rzadką grupą przewlekłych chorób skóry, którą cechuje obecność charakterystycznych cech morfologicznych i histopatologicznych. Klinicznie zmiany skórne manifestują się jako grudka, która rozrastając się obwodowo, przechodzi ewolucję w lekko zanikowe ognisko z delikatnie złuszczającą się obwódką [1].

W obrazie histopatologicznym charakterystyczne jest nadmierne rogowacenie $\mathrm{z}$ obecnością parakeratotycznych blaszek rogowych, tzw. cornoid lamellae, wychodzących z ognisk ścieńczałej lub nieprawidłowej warstwy ziarnistej [2].

Klasyczna postać schorzenia została po raz pierwszy opisana w 1893 r. przez Vittorio Mibellego. Stworzył on wówczas pojęcie porokeratoza, które w świetle obecnych danych wydaje się nieprawidłowe, ponieważ zaburzenia te nie mają związku z ujściem gruczołów potowych ekrynowych [3]. Wyróżnia się kilka odmian choroby (tab. 1) [4-6].

Porokeratoza nie jest jedynie defektem estetycznym, ale stanowi stan przednowotworowy. Ryzyko transformacji szacuje się na 7,5-11,6\% [2]. Do zmian chorobowych, które mogą się rozwinąć na podłożu ognisk porokeratozy, należą rak kolczystokomórkowy, rak podstawnokomórkowy oraz choroba Bowena [7-9]. Zmiany skórne wymagają aktywnej obserwacji. W leczeniu stosuje się retinoidy miejscowo [2] lub ogólnie [10], preparaty z 5-fluorouracylem [11], imikwimodem, diklofenakiem, analogami witaminy D, krioterapię, laseroterapię, elektrokoagulację, dermabrazję, terapię fotodynamiczną, a nawet chirurgiczne wycięcie pojedynczych zmian [12].

\section{CEL PRACY}

Celem pracy było przedstawienie i omówienie przypadku rodzinnego występowania porokeratozy Mibellego u 11-letniej dziewczynki i jej 40-letniej matki.

\section{OPIS PRZYPADKU}

Dziewczynka 11-letnia zgłosiła się do kliniki z matką z powodu wyraźnie odgraniczonych, lekko zanikowych, obrączkowatych ognisk z widoczną uniesioną, delikatnie złuszczającą się, hiperkeratotyczną obwódką. Zmiany zajmowały powierzchnię wyprostną prawej 
Table I. Classification of porokeratosis [4-6]

\begin{tabular}{|c|c|}
\hline Type & Characteristics \\
\hline Porokeratosis of Mibelli & $\begin{array}{l}\text { - Most often individual, slowly growing plaques found asymmetrically on } \\
\text { extensor surfaces of limbs } \\
\text { - More common in men; may appear at every age } \\
\text { - Types: } \\
\text { - Linear porokeratosis } \\
\text { - Giant porokeratosis }\end{array}$ \\
\hline Disseminated superficial actinic porokeratosis (DSAP) & $\begin{array}{l}\text { - Foci are less demarcated; a more intense inflammation may occur on } \\
\text { back and extensor surfaces of limbs } \\
\text { - Usually occurs between the third and fourth decade of life; more often } \\
\text { in women with skin type I or II according to Fitzpatrick scale; correlates } \\
\text { with exposure to solar radiation }\end{array}$ \\
\hline Disseminated superficial porokeratosis (DSP) & $\begin{array}{l}\text { - No connection with solar radiation; may concur with amyloid deposition } \\
\text { in skin, and appear in children }\end{array}$ \\
\hline Punctate palmoplantar porokeratosis & - Small spikes on hands and feet; they may be painful \\
\hline Punctate disseminated palmoplantar porokeratosis & - Disseminated lesions; initially on hands and feet \\
\hline Porokeratosis ptychotropica & - Involvement of buttocks and anogenital area \\
\hline
\end{tabular}

Tabela I. Podział porokeratoz [4-6]

\begin{tabular}{|c|c|}
\hline Odmiana & Charakterystyka \\
\hline $\begin{array}{l}\text { Klasyczna porokeratoza Mibellego (porokeratosis } \\
\text { of Mibelli) }\end{array}$ & $\begin{array}{l}\text { - Najczęściej pojedyncze, wolno rosnące blaszki zlokalizowane } \\
\text { niesymetrycznie na wyprostnych powierzchniach kończyn } \\
\text { - Częściej u mężczyzn, może pojawiać się w każdym wieku } \\
\text { - Odmiany: } \\
\text { - Porokeratoza linijna } \\
\text { - Porokeratoza olbrzymia }\end{array}$ \\
\hline $\begin{array}{l}\text { Rozsiana powierzchowna porokeratoza słoneczna } \\
\text { (disseminated superficial actinic porokeratosis - DSAP) }\end{array}$ & $\begin{array}{l}\text { - Ogniska są mniej odgraniczone i może występować większy stan } \\
\text { zapalny, najczęściej na plecach, wyprostnych powierzchniach kończyn } \\
\text { - Zwykle pojawia się między trzecią a czwartą dekadą życia, częściej } \\
\text { u kobiet z fototypem I lub II wg Fitzpatricka, koreluje z ekspozycją } \\
\text { na promieniowanie słoneczne }\end{array}$ \\
\hline $\begin{array}{l}\text { Rozsiana powierzchowna porokeratoza (disseminated } \\
\text { superficial porokeratosis - DSP) }\end{array}$ & $\begin{array}{l}\text { - Bez związku z promieniowaniem słonecznym, może współistnieć } \\
\text { z odkładaniem amyloidu w skórze i pojawiać się u dzieci }\end{array}$ \\
\hline Porokeratosis palmoplantaris punctata & - Drobne kolce na dłoniach i stopach, mogą być bolesne \\
\hline Porokeratosis palmoplantaris punctata disseminata & - Zmiany rozsiane, początkowo na dłoniach i stopach \\
\hline Porokeratosis ptychotropica & - Z zajęciem okolic pośladkowej i anogenitalnej \\
\hline
\end{tabular}

dorsal surface of her right hand when the girl was 5 . The lesions were expanding outwards and appeared in other areas of the upper right limb.

Similar lesions were present in the 40-year-old mother of the girl. Exanthemata were spread on extensor surfaces of both her shins. The history confirmed that maternal grandmother also had such lesions - on her shoulder. No pain reported in the interview. The patients denied excessive exposure to sun and post-solar nature of the lesions.

At the Clinic skin biopsies were taken from both patients that correlated with the clinical presentations, and consequently, confirmed the diagnosis. Histopathologically, in the 11-year-old girl there was thin, acanthotic epidermis with hyperkeratosis, parakeratosis, cornified plugs, and spongiosity. In the areas of epidermal recesses, there was a visible atrophy of granular layer. A vacuolar degeneration of numerous basal cells, and a narrow kończyny górnej i wystąpiły w 5. roku życia. Początkowo pojawiły się na powierzchni grzbietowej ręki, a następnie stopniowo powiększały się obwodowo.

Podobne zmiany skórne obecne były u 40-letniej matki dziewczynki. Wykwity były zlokalizowane na powierzchniach wyprostnych obu podudzi. Z wywiadu ustalono, że u babki ze strony matki obecne były również podobne zmiany na skórze ramienia. Zmianom nie towarzyszyły dolegliwości podmiotowe. Pacjentki negowały nadmierną ekspozycję na słońce i posłoneczny charakter zmian.

$\mathrm{W}$ trakcie pobytu w klinice u obu pacjentek pobrano wycinki skóry do badania histologicznego, które w korelacji z obrazem klinicznym potwierdziły rozpoznanie. W obrazach histopatologicznych u 11-letniej dziewczynki stwierdzono cienki, akantotyczny naskórek z hiperkeratozą, parakeratozą, tworzeniem czopów rogowych i obecnością spongiozy. W okolicy wgłębień naskórka widoczny był zanik warstwy ziar- 


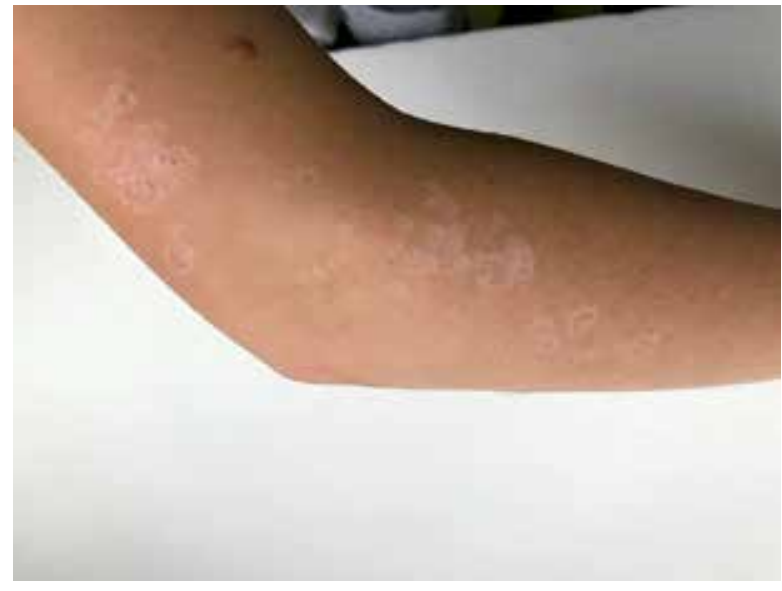

Figure I. Well demarcated, multiple lesions with hyperkeratotic border and atrophic centre on right upper limb in a I | -year-old gir Rycina I. Dobrze odgraniczone, mnogie zmiany z rogowaciejącym brzegiem i lekko zanikową częścią środkową na skórze prawej kończyny górnej u I I-letniej dziewczynki

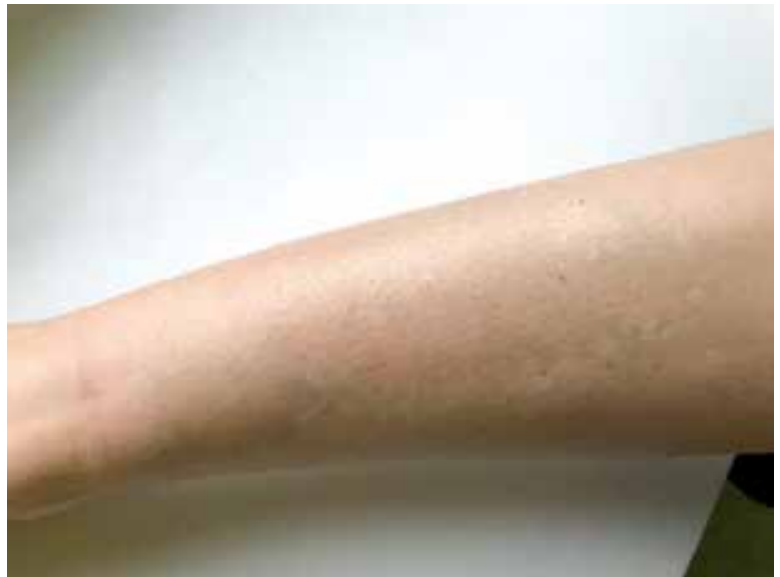

Figure 2. Well-demarcated lesions with hyperkeratotic border and atrophic centre on shins in a 40-year-old woman

Rycina 2. Dobrze odgraniczone zmiany z rogowaciejącym brzegiem i lekko zanikową częścią środkową na podudziach u 40-letniej kobiety

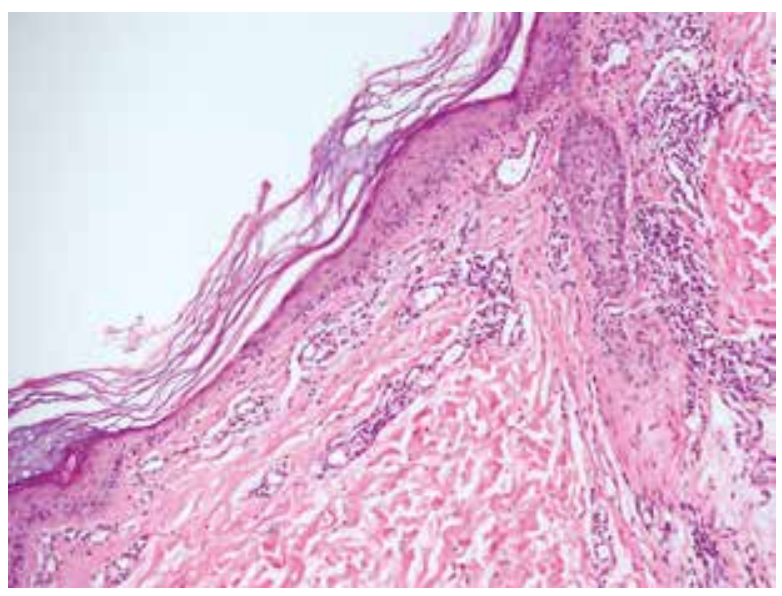

Figure 3. Histologic aspect of porokeratosis

Rycina 3. Obraz histopatologiczny porokeratozy

belt of collagen degeneration under the epidermis were also present. Skin adnexa were present. In the 40-year-old mother a microscopic image revealed an acanthotic epidermis with hyperkeratosis and formation of cornified plugs at hair follicles' orifices. Signs of parakeratosis were present here and there within epidermal recesses. Below these foci there was no granular layer of the epidermis. Features characteristic for porokeratosis were of discrete nature.

In both female patients treatment involved topical $0.1 \%$ adapalene cream. The patients remain under the care of Dermatology Clinic (figs. 1-3).

\section{DISCUSSION}

Etiopathogenesis of porokeratosis appears to be complex and multicausal. It is assumed that skin lesions appear as a result of peripheral proliferation of abnormal keratinocyte clone. The hypothesis is nistej. Obecne było zwyrodnienie wodniczkowe oraz nieswoiste nacieki limfocytarne. Przydatki skóry były zachowane. U 40-letniej matki w obrazie mikroskopowym obserwowano akantotyczny naskórek z hiperkeratozą i tworzeniem czopów rogowych w miejscu ujść mieszków włosowych. Ogniskowo w obrębie zagłębień naskórka obecne były cechy parakeratozy. Poniżej tych ognisk obserwowano zanik warstwy ziarnistej. Charakterystyczne cechy dla rogowacenia kanalikowego miały bardziej dyskretny charakter niż u córki.

W leczeniu u obu pacjentek zastosowano miejscowo $0,1 \%$ adapalen w kremie. Pacjentki są pod opieką poradni dermatologicznej (ryc. 1-3).

\section{OMÓWIENIE}

Etiopatogeneza rogowacenia kanalikowego jest złożona i wieloczynnikowa. Zakłada się, że zmiany skórne powstają wskutek obwodowego namnażania się klonu nieprawidłowych keratynocytów. Hipotezę 
confirmed by identification of DNA aneuploidy, increased number of keratinocytes in phases $S$ and G2/M of the cell cycle, as well as increased expression of p53 oncoproteins and $\mathrm{Rb}$, inter alia, in the proximity of cornoid lamella [3]. Factors that may activate clonal expansion of abnormal keratinocytes include: genetic factors, ultraviolet radiation, immune impairment, infections, injuries, drugs and chemical substances (table 2).

Literature offers descriptions of familial occurrence of a classic form of porokeratosis of Mibelli, its linear variation or punctate palmoplantar (palmoplantaris punctata) and punctate disseminated (punctata et disseminata) porokeratoses. Mutations in the following genes were identified: MVK (mevalonate kinase), MVD (mevalonate pyrophosphate decarboxylase), PMVK (phosphomevalonate kinase), FDPS (farnesyl diphosphate synthase) [13] localized within 1, 2, 12, $16,18,20,22$ chromosomes [14]. Inheritance of these genes is autosomally dominating with incomplete penetrance. Occasional cases were caused by somatic mutations $[3,15]$.

In the described case, skin lesions secondary to porokeratosis of Mibelli occurred in the maternal line in three generations, i.e. in a grandmother, girl's mother (her brother does not exhibit skin lesions of such nature), and one daughter. The lesions had similar morphology and histopathology. They covered two different areas: in the mother they were spread on shin skin, and in the daughter they were linearly grouped within the upper right limb. The interview tę potwierdza identyfikacja aneuploidalnego DNA, stwierdzenie zwiększonej liczby keratynocytów w fazie cyklu komórkowego S i G2/M oraz zwiększonej ekspresji m.in. onkoprotein p53 oraz $\mathrm{Rb}$ w pobliżu cornoid lamellae [3]. Do czynników, które mogą aktywować klonalną ekspansję nieprawidłowych keratynocytów, zalicza się: czynniki genetyczne, promieniowanie ultrafioletowe, upośledzenie odporności, infekcje, urazy, leki oraz substancje chemiczne (tab. 2).

W piśmiennictwie dostępne są opisy rodzinnego występowania klasycznej postaci porokeratozy Mibellego, jej linijnej odmiany oraz porokeratoz palmoplantaris punctata i punctata disseminata. Zidentyfikowano mutacje m.in. w genach MVK (mevalonate kinase), MVD (mevalonate pyrophosphate decarboxylase), PMVK (phosphomevalonate kinase), FDPS (farnesyl diphosphate synthase) [13] z lokalizacją w obrębie chromosomów 1, 2, 12, 16, 18, 20, 22 [14]. Dziedziczenie tych genów jest autosomalnie dominujące z niepełną penetracją. Przypadki sporadycznie spowodowane były mutacjami somatycznymi [3, 15].

W przedstawionym przypadku zmiany skórne w przebiegu porokeratozy Mibellego występowały w linii żeńskiej w trzech pokoleniach, tj. u babki, matki (u brata matki nie stwierdzono zmian) i u jedynej córki. Zmiany miały zbliżoną do siebie morfologię oraz obraz histopatologiczny. Były różnie zlokalizowane: $u$ matki rozsiane na skórze podudzi, a u córki zgrupowane linijnie w obrębie prawej kończyny górnej. Z wywiadu wynikało, że

Table 2. The triggering factors in the development of porokeratosis [3]

\begin{tabular}{ll}
\hline Genetic factors & Incl. MVK, MVD, PMVK, FDPS dominating autosomal inheritance with incomplete penetrance \\
\hline Ultraviolet radiation & Documented in DSAP; also artificial UV sources, e.g. UVB, PUVA \\
\hline Immune impairment, infections & $\begin{array}{l}\text { Post organ transplants; during immunosuppressive therapy; in solid neoplasms; } \\
\text { myeloproliferative disorders; infections: HIV, HBV, HCV, HPV; autoimmune and inflammatory } \\
\text { diseases }\end{array}$ \\
\hline Injuries & $\begin{array}{l}\text { There are descripted cases of lesion development in scar tissue post burns, and at } \\
\text { haemodialysis accesses }\end{array}$ \\
\hline Drugs and chemical substances & $\begin{array}{l}\text { Described case of DSP after diuretics (furosemide, hydrochlorothiazide); after long-time } \\
\text { exposure to benzene, benzochlorothiazide, after treatment with TNF- } \alpha, \text { antibiotics, } \\
\text { hydroxycarbamide and topical glucocorticosteroids }\end{array}$ \\
\hline
\end{tabular}

Tabela 2. Czynniki wyzwalające rozwój porokeratozy [3]

\begin{tabular}{ll}
\hline Czynniki genetyczne & M.in. MVK, MVD, PMVK, FDPS dziedziczenie autosomalnie dominujące z niepełną penetracją \\
\hline Promieniowanie ultrafioletowe & Udokumentowane w DSAP, również sztuczne źródła UV, np. UVB, PUVA \\
\hline Upośledzenie odporności, infekcje & $\begin{array}{l}\text { Po przeszczepieniach narządów, w trakcie leczenia immunosupresyjnego, w przebiegu } \\
\text { nowotworów litych, chorób rozrostowych szpiku, infekcji, m.in. HIV, HBV, HCV, HPV, } \\
\text { chorób autoimmunologicznych i zapalnych }\end{array}$ \\
\hline Urazy & Opisano przypadki rozwoju zmian w bliznach po oparzeniu, miejscach dostępu naczyniowego \\
& do hemodializy \\
\hline Leki i substancje chemiczne & Opisano przypadki DSP po diuretykach (furosemid, hydrochlorotiazyd), po długotrwałej \\
& ekspozycji na benzen, benzochlorotiazyd, po leczeniu inhibitorami TNF- $\alpha$, antybiotykami \\
& i hydroksymocznikiem oraz miejscowymi glikokortykosteroidami
\end{tabular}


confirmed that the grandmother of the girl had lesions on her upper limb.

\section{CONCLUSIONS}

Porokeratoses constitute a rare group of diseases characterized by clonal keratinization disorders. Etiopathogenesis remains unclear, whereas literature offers descriptions of familial occurrence of the disease. The presented case regards porokeratosis of Mibelli in the maternal line in three generations. Further research is required to explain etiopathology of the disease with an emphasis put on participation of specific genes responsible for skin lesion development.

\section{CONFLICT OF INTEREST}

The authors declare no conflict of interest. u babki dziewczynki zmiany również zlokalizowane były na kończynie górnej.

\section{WNIOSKI}

Porokeratozy stanowią rzadką grupę chorób charakteryzującą się klonalnymi zaburzeniami rogowacenia. Etiopatogeneza nie jest wciąż do końca poznana, a w piśmiennictwie dostępne są opisy rodzinnego występowania choroby. Opisywany przypadek dotyczy porokeratozy Mibellego w linii żeńskiej w trzech pokoleniach. Konieczne są dalsze badania nad wyjaśnieniem ścieżek etiopatologicznych schorzenia ze szczególnym uwzględnieniem udziału swoistych genów odpowiedzialnych za rozwój zmian skórnych.

\section{KONFLIKT INTERESÓW}

Autorzy nie zgłaszają konfliktu interesów.

\section{References}

\section{Piśmiennictwo}

1. Jaworek A.K., Pastuszczak M., Węgiel M.J., Dyduch G., Jaworek M., Wojas-Pelc A.: Rozsiana powierzchowna posłoneczna porokeratoza - opis przypadku klinicznego. Dermatol Prakt 2013, 5, 41-46.

2. Roziewska D., Szczerkowska-Dobosz A., Komorowska O.: Rozsiana powierzchowna porokeratoza - skuteczne leczenie miejscowe retinoidami. Przegl Dermatol 2010, 97, 191-195.

3. Kanitakis J.: Porokeratoses: an update of clinical, aetiopathogenic and therapeutic features. Eur J Dermatol 2014, 24, 533-544.

4. Biswas A.: Cornoid lamellation revisited: apropos of porokeratosis with emphasis on unusual clinicopathological variants. Am J Dermatopathol 2015, 37, 145-155.

5. Braun-Falco O.: Dermatologia. W.H.C. Burgdorf, G. Plewig, H.H. Wolf, M. Landthaler (eds.). Wydawnictwo Czelej, Lublin, 2011, 870-871.

6. Contreras-Ruiz J., Toussaint-Caire S., Torres-Camacho P., Villa-Castro V.B.: Porokeratosis ptychotropica: a diagnostic and therapeutic challenge. J Eur Acad Dermatol Venereol 2018, 32, e114-e115.

7. Shrum J.R., Cooper P.H., Greer K.E., Landes H.B.: Squamous cell carcinoma in disseminated superficial actinic porokeratosis. J Am Acad Dermatol 1982, 6, 58-62.

8. Maubec E., Duvillard P., Margulis A., Bachollet B., Degois G., Avril M.F.: Common skin cancers in porokeratosis. Br J Dermatol 2005, 152, 1389-1391.

9. Friedman B., Golubets K., Ho J., Patton T.: Linear porokeratosis associated with multiple squamous cell carcinomas. Cutis 2017, 100, E11-E14.

10. Hong J.B., Hsiao C.H., Chu C.Y.: Systematized linear porokeratosis: a rare variant of diffuse porokeratosis with good response to systemic acitretin. J Am Acad Dermatol 2009, 60, 713-715.

11. McDonald S.G., Peterka E.S.: Porokeratosis (Mibelli): treatment with topical 5-fluorouracil. J Am Acad Dermatol 1983, 8, 107-110.

12. Weidner T., Illing T., Miguel D., Elsner P.: Treatment of porokeratosis: a systematic review. Am J Clin Dermatol 2017, 18, 435-449.

13. Sun R.F., Chen H., Zhu W., Lian S.: Dermoscopic features and gene mutation in the mevalonate pathway of five sporadic patients with porokeratosis. Chin Med J (Engl) 2017, 130, 1747-1748.

14. OMIM Entry Search - porokeratosis. http:/ $/$ www.omim.org/search/?index=entry\&search=porokeratosis\&sort=score + desc $\% 2 C+$ prefix_sort+desc\&start $=1 \&$ limit $=10$. Accessed December 21, 2017.

15. Anderson D.E., Chernosky M.E.: Disseminated superficial actinic porokeratosis. Arch Dermatol 1969, 99, 408-412.

Received: 12.01 .2018

Accepted: 9.06 .2018

Otrzymano: $12.01 .2018 \mathrm{r}$.

Zaakceptowano: $9.06 .2018 \mathrm{r}$.

How to cite this article

Tomaszewska K.A., Dominiak M., Zalewska-Janowska A.M., Kaszuba A.: Familial porokeratosis Mibelli. Dermatol Rev/Przeg1 Dermatol 2018, 105, 619-624. DOI: https://doi.org/10.5114/dr.2018.79174. 